Байкальский государственный университет, 2. Иркутск, Российская Федеращия

Д. В. Паршин Восточно-Сибирский институт Министерства внутренних дел Российской Федерации, г. Иркутск, Российскал Федерация

\title{
ИСПОЛЬЗОВАНИЕ ПРИЕМОВ ПСИХОТЕРАПИИ И РЕЛАКСАЦИИ В ХОДЕ ПРОВЕДЕНИЯ ДОПРОСОВ ПРИ РАССЛЕДОВАНИИ ПРЕСТУПЛЕНИЙ ПО ФАКТУ ХИЩЕНИЙ БЮДЖЕТНЫХ СРЕДСТВ
}

\begin{abstract}
АННОТАЦИЯ. Обязательным следственным действием в практике расследования уголовных преступлений является допрос, в ходе которого могут быть использованы тактические приемы с применением психофизиологических методов и психотерапевтических приемов для цели выявления ложных показаний подозреваемого или обвиняемого лица. Существует целый ряд тактических приемов допроса в условиях конфликтной ситуации. Приемы психотерапии и релаксации, проводимые при расследовании преступлений, способствует допрашиваемому в восстановлении действительной картины при расследовании хищений в бюджетной сфере. кЛЮчЕВЫЕ СЛОВА. Психология; психофизиология; допрос; тактический прием; ложь; конфликтная ситуация; преступление.

ИНФОРМАЦИЯ О СТАТЬЕ. Дата поступления 11 марта 2017 г.; дата принятия к печати 23 марта 2017 г.; дата онлайн-размещения 31 марта 2017 г.
\end{abstract}

V. S. Ishigeyev

Baikal State University, Irkutsk, Russian Federation

D. V. Parshin

East-Siberian Institute of Ministry of Interior Affairs, Irkutsk, Russian Federation

\author{
USING METHODS OF PSYCHOTHERAPY AND RELAXATION \\ IN INVESTIGATING CRIMES IN THE COURSE \\ OF INTERROGATION UPON EMBEZZLEMENT OF PUBLIC FUNDS
}

\begin{abstract}
Interrogation is an obligatory investigative action in the practice of investigating criminal crimes, during which one can employ tactical methods involving the use of psycho-physiological and psycho-therapeutic methods in order to discover false testimony of the suspect or the accused. There is a number of tactical methods of interrogation in terms of conflict situations. The methods of psychotherapy and relaxation exercised in investigating crimes assist the interrogee to restore the actual picture in investigating the embezzlement of public funds.

KEYWORDS. Psychology; psycho-physiology; interrogation; tactical method; conflict situation; crime.

ARTICLE INFO. Received March 11, 2017; accepted March 23, 2017; available online March 31, 2017.
\end{abstract}

В судебно-следственной практике значение объективных сведений, собранных в качестве доказательств составляет основополагающую значимость для установления вины. Лица, проводящие предварительное или судебное следствие получают важную информацию при производстве допроса участников уголовно-

(ㄷ В. С. Ишигеев, Д. В. Паршин, 2017

\section{Baikal Research Journal}


го процесса. Между тем, нежелание подозреваемых в совершении преступления давать показания, а также попытки дачи ими ложные показаний, ставят процедуру допроса перед необходимостью применять приемы, связанные с воздействием на поведение допрашиваемого через его личностные особенности и психические функции. Профессор О. Я. Баев полагает, что «...традиционно причины следственных ошибок в самом общем виде усматриваются в недостаточно высоком профессиональном, интеллектуальном и нравственном уровне следователей, их допускающих" [1, с. 72]. В этой части С. Б. Россинский также справедливо утверждает, что в следственной и судебной практике наблюдаются серьезные затруднения, связанные с производством следственных действий, а также с проверкой и оценкой их результатов [2, с. 16]. С учетом этого, применение в следственной практике важных, смежных с криминалистикой наук: психологии и психофизиологии поведения требует безусловного владения знаниями в этих областях. В арсенале лица, проводящего допрос, должны присутствовать знания психологии личности, поведения, конфликта, а также навыки применения отдельных методик, требующих от следователя или судьи владения представлениями в области психофизиологии. Психика человека имеет огромный информационный потенциал, а диагностика поведения допрашиваемого посредством методов психологического анализа, напрямую влияет на эффективность производства следственного действия и, в целом, на качество расследования.

Применение психологических методов в раскрытии и расследовании преступлений наделяет лицо проводящее дознание или следствие интеллектуальными преимуществами, поскольку в сфере психологии личности преступника а также в психофизиологии его поведения, кроются дополнительные возможности для әффективной работы с когнитивным компонентом психики подозреваемых и обвиняемых. Эти знания включают в себя, прежде всего, естественнонаучные основы оценки аналитико-синтетической функции психики человека в ответ на внешние вербальные и невербальные раздражители. Психофизиолог, используя методологию своей науки, будет стараться установить как состояние страха изменяет функционирование тех или иных физиологических систем и присущи ли эти изменения только состоянию страха или они носят неспецифический характер и наоборот, регистрируя изменения физиологических показателей, попытается определить испуган ли объект его наблюдений. Другими словами, изучая физиологические процессы, он ищет объективные критерии для оценки психических проявлений поведения (в широком смысле этого понятия) человека.

Таким образом, в основе психофизиологии лежит довольно смелое устремление психологов объяснить психические явления через изучение сопряженных с ними физиологических, материальных процессов.

Помимо индивидуальных знаний и навыков в качестве объективных верификаторов при допросах (опросах) могут выступать технические средства (полиграф, майн-ридер, тесты СМИЛ), реализуемые через современные методы изучения личности. Особое место в оценке рефлексии допрашиваемого лица занимает перманентный контроль за психологическими и психофизиологическими особенностями проявления реакций на раздражение демонстрируемые человеком во время допроса. Известно, что формы и виды позитивных, негативных, или нейтральных реакции человека, отражающиеся в его поведение при допросе могут послужить основой для правильного понимания психологического противодействия или попытки сокрытия криминалистически значимой информации [3, с. 13].

Зачастую, сам находясь в состоянии информационной неопределенности, следователь имеет перспективу применения в тактике допроса всего комплекса пси-

\section{Baikal Research Journal}


хологических методов, и именно осознание характера информационной неопределенности, существующей на момент проведения допроса, помогает следователю спланировать порядок и определить тактику проведения следственного действия $[4$, с. 16]. При этом он ведь вправе воздействовать и на сознание и на подсознание допрашиваемого, побуждая его к откровенности или лжи.

Возникающие затруднения связаны, в том числе, с неспособностью допрашивающего владеть элементарными приемами психотерапии и релаксации. Использование тактических приемов, по мнению Т. С. Волчецкой, зависит от конкретной сложившейся следственной ситуации и ее оценки следователем [5, с. 17]. При этом допрос лица, дающего ложные показания, имеет свои особенности. Тактические приемы, рекомендуемые для изобличения ложных показаний, условно делят на несколько групп эмоционального, логического воздействия. Однако к использованию тех или иных тактических приемов необходимо подходить вдумчиво и осторожно, на что указывает А. Г. Бедризов: «...в процессе допроса в ходе использования ряда тактических приемов, рекомендованных криминалистикой, следователь и свидетель в той или иной степени невольно оказывают психологическое давление друг на друга» [6, с. 122]. В конфликтных ситуациях оба взаимодействующих лица, как допрашиваемый, так и производящий допрос, эмоционально напряжены и возбуждены, в результате чего возникают психологические срывы, присущие обеим сторонам. Вполне очевидно, что тактика действия следователя при проведении допроса зависит и от особенностей психических реакций допрашиваемого. «Распознавание образа допрашиваемого создает предпосылки для решения ряда важных тактических задач. В первую очередь таких задач, как определение следователем приемов установления и поддержания психологического контакта с допрашиваемым. Важнейшей задачей, опирающейся на те же основания, является распознавание и преодоление лжи допрашиваемого" [7, с. 106]. При допросе информация извлекается из сферы вербально-обобщенного отражения субъекта. Когнитивная сфера психики в таких случаях наиболее активно вовлечена в процесс, при этом эмоционально-волевая сфера находится в заведомо зависимом от предпринятого психологического приема состояния. Так, к примеру, путем жертвенно-реливантного вербального стимула можно активизировать поведенческие реакции и обнаружить, что допрашиваемый начинает проявлять вегетативные реакции, на первый взгляд, мало значимый вопрос. Информационный материал извлекается из глубины памяти, следовательно, психическую функцию-память, следует активизировать и настроить на высший уровень репродукции. Это можно достичь с помощью соответствующего музыкального сопровождения, как к примеру это делал Н. Н. Китаев, допрашивая серийного убийцу Кулика или вербального жертвенно-реливантного построения вопроса. В область памяти входит и представление о обстановке, ярких образах, сопровождавших обсуждаемое событие Следователь должен учитывать основные закономерности процессов запоминания и забывания, в том чисел временные показатели. Общеизвестно, что в первые несколько суток человек готов к воспроизводству, известной ему информации и помнит максимально приближенную к реальному событию информационную модель, которая по истечению времени деформируется [8, с. 93]. Иногда истинная память может фрагментарно подменяться конфабуляциями, и можно легко установить проверочными или нейтральными вопросами.

Одним из важнейших условий устранения конфликтных ситуаций при допросе, например, свидетелей является установление его мотивации. С точки зрения Е. П. Ищенко: «...сущность психологического воздействия состоит в использовании тактических приемов, обеспечивающих наиболее эффективную

\section{Baikal Research Journal}

электронный научный журнал Байкальского государственного университета 
форму предъявления доказательственных материалов, направленных на изменение хода психических процессов, субъективной позиции допрашиваемого, на убеждение его в необходимости дать показания, соответствующие действительности" [9, с. 243]. Иными словами непрерывное изменение модуса раздражающих сигналов позволяет следователю дезориентировать аналитико-синтетическую деятельность психики допрашиваемого, а формирование динамического эмоционально-волевого процесса обеспечивает утрату контроля над эмоциями, что может положительно отразиться в получении конкретной, доказательной информации.

Однако, использование психолого-криминалистического портрета, в противовес оценки психотипических реакций в практической деятельности лиц, осуществляющих производство предварительного расследования дел, представляет определенную сложность. Так согласно проведенным нами исследованиям, 50 \% опрошенных следователей заявили о наличии у них психологических проблем, возникающих при производстве допросов мошенников, 60 \% опрошенных предпочли бы совместную деятельность с профессиональными психологами, и только $5 \%$ реально обращаются к их помощи. Таким образом, использование следователем психолого-криминалистического портрета при производстве допросов в условиях конфликтной ситуации представляет собой напряженный в психологическом плане, тактически сложный и многообразный по количеству применяемых приемов процесс. Знание психологических закономерностей, формирующих представление о достоверности показаний у рассматриваемой категории лиц, умелое оперирование тактическими приемами, преодоление лжи и психологической защиты преступника в конечном итоге подчиненно основной цели допроса - получению объективной, процессуально значимой информации об обстоятельствах, подлежащих доказыванию при расследовании хищений бюджетных средств.

В этой связи, казалось бы наиболее эффективно применение приборных методов установления знаний преступной вины, преимущественно с использованием полиграфа и других технических средств регистрации психофизиологических реакций. Но подобную оценку можно осуществлять и при визуальном контроле за реакцией допрашиваемого, например, наиболее демонстративными проявлениями психоэмоционального напряжения могут служить: двигательное беспокойство, внешние реакции вегетативной нервной системы (покраснение кожи лица, сухость губ, показатели частоты пульса) и другие реакции. Помимо этого, вопрос о психологическом анализе поведения личности в начале допроса, в его активной и заключительной части необходимо рассматривать как отдельные психофизиологические характеристики. В условиях усталости, ослабленного контроля за когнитивными функциями, вероятность установления объективных показателей достоверных ответов значительно повышается, одновременно снижается выраженность вегетативных реакций и других психофизиологических проявлений, что затрудняет визуальный контроль за допрашиваемым. В таких случаях целесообразно переходить на психологический прием - логического воздействия, но лишь в случае достаточного уровня интеллекта у допрашиваемого, а также с учетом его психотипа, к примеру у лиц с проявлениями параноидного и гипертимного типа личности. Эффективным в таких случаях будет предъявление, на заключительной стадии допроса очевидных доказательств, в первую очередь вещественных, которые опровергают данные ранее показания. Практике известны два вида предъявления доказательств: от менее веских - к более веским, либо предъявление более значительного доказательства в начале устранения конфликта, причем определение порядка предъявления доказа-

\section{Baikal Research Journal}


тельств необходимо устанавливать в зависимости от личностных характеристик допрашиваемого и самого характера доказательств. Так для психотипа с выраженными признаками истероидной личности следует предъявлять доказательства по мере утраты уверенности допрашиваемого в своем превосходстве над следователем. В качестве сигнала, о целесообразности предъявления вещественных доказательств можно использовать прекращение активной наступательной позиции допрашиваемого, т. е. сигнала о исчерпании им ресурсов аналитико-синтетической деятельности и перехода в возбуждение эмоционально-волевой сферы. В целом эффективность такого средства тактического воздействия подтверждена правоприменительной практикой. Кроме того, во всех ситуациях следователь должен сохранять паттернистскую позицию, постоянно демонстрацию свое превосходство, «знания тайны», психическую устойчивость и уравновешенность. Как верно указывают А. Ю. Головин и Н. В. Бугаевская: «Умелое использование в ходе допроса доказательств, опровергающих уклончивые ответы или лживые показания, может послужить эффективным средством получения правдивых показаний» [10, с. 11]. При конфликтных ситуациях можно рекомендовать, рефлексивные комбинации, преследующие цель истребования информации, либо, создающие условия, обеспечивающие формирование допрашиваемым неправильного представления об осведомленности следователя, его планах и состоянии расследования.

Приемы логического воздействия достаточно әффективны при необходимости разоблачения подтверждения свидетелем ложного алиби преступника. Как верно указывают А. В. Варданян и О. Н. Алексиенко, «...ложное алиби выступает как один из приемов (способов) противодействия, при этом содержание деятельности по его реализации тесно связано и взаимообусловлено с различными другими приемами противодействия» $[11$, с. 36$]$, в том числе с дачей ложных показаний свидетелями. В таком случае опровержение показаний возможно путем детального допроса, чередующихся вербальных раздражителей свидетеля с целью выявления неизбежных противоречий в показаниях. Ложь плохо запоминается им, и при постоянно изменяющейся форме вопроса (стимула) может проявиться и соответственно, воспроизводится в ином виде, либо в нескольких искаженных вариантах ответа. Например, косвенный допрос, предполагающий постановку вопросов, по мнению следователя, второстепенных для допрашиваемого, и маскирующих основной - значимый и срываемый допрашиваемым. Так, в случае обнаружения на месте происшествия следов пальцев рук предполагаемого преступника, свидетелю необходимо сначала задать вопрос, преследующий исключение возможности достоверно утверждать, что следы оставлены до совершения преступления. В этом случае допрашиваемый, считая для себя эти обстоятельства менее «опасными", может рассказать о них, предоставив следователю определенную информацию для получения ответа на замаскированный вопрос [12, с. 420]. Достаточно действенными являются приемы, которые направлены на воссоздание ситуации «проговорок» при предоставлении возможности пространно излагать показания в расчете на сообщение достоверных данных среди ложной информации, которые типично попадают в показания в результате непонимания их значимости. Суть «внезапности», как тактического приема представляется как неожиданный для допрашиваемого вопрос, который не связан с предыдущим. В условиях тактической комбинации прием «предъявление доказательств» целесообразно сочетать с «допущением легенды» и «пресечением лжи».

При использовании «допущения легенды» свидетелю предоставляется возможность излагать обстоятельства ложной легенды. Причем целесообразно данный прием применять в сочетании с другими, например, «пресечением лжи»,

\section{Baikal Research Journal}

электронный научный журнал Байкальского государственного университета 
повторностью, внезапностью, последовательностью допроса. Косвенный вопрос возможно сочетать с «форсированием темпа допроса». В этом случае, как выбор соответствующей тактики связан с личностными качествами допрашиваемого и, прежде всего, его моральной сензитивностью - чувствительностью к разоблачающим действиям следователя, и своевременное выявление этого состояния и убеждении допрашиваемого в целесообразности перехода от лживых к правдивым показаниям - одна из тактических задач следователя на что обращает внимание Е. П. Ищенко [8, с. 93]. В таких случаях психологическое воздействие на опрашиваемого должно носить характер нарастающего натиска в котором вербальные стимулы дающие предпосылке к даче объективных показаний должны контролироваться поведенческими реакциями допрашиваемого: изменением позы в отношении следователя (зрительный контакт, поза открытости и др.).

Таким образом, в ассортименте тактических приемов психологии общения в условиях конфликта набор средств выявления и оценки достоверности получаемой информации может быть существенно расширен путем привлечения методов аналитической психологии и психофизиологии. Подводя определенный итог, следует констатировать, что своевременное выявление лжи и способность следователя использовать отдельные приемы психотерапии и рефлексии при проведении допросов, а также способность своевременно верифицировать и осуществлять коррекцию проведения допроса в сложных следственных ситуациях, позволяет эффективно проводить его и получать объективные показания. Задачей лица, проводящего допрос и обладающего соответствующими знаниями и навыками в области психологии конфликта, психофизиологии поведения, является мотивационно переориентировать допрашиваемого на дачу правдивых показаний, что служит залогом успешной работы следователя (дознавателя).

\section{Список использованной литературы}

1. Баев О. Я. К методологии следственной тактики (причины следственных ошибок) / О. Я. Баев // Законы Росси: опыт, анализ, практика. - 2015. - № 2. - С. 70-78.

2. Россинский С. Б. Понятие и сущность следственных действий в уголовном судопроизводстве: дискуссия продолжается / С. Б. Россинский // Законы Росси: опыт, анализ, практика. - 2015. - № 2. - C. 16-31.

3. Пеленицин А. Б. О научной обоснованности применения полиграфа / А. Б. Пеленицин // Эксперт-криминалист. - 2011. - № 2. - С. 12-15.

4. Андреев А. А. Тактика допроса подозреваемого и обвиняемого в сложных следственных ситуациях / А. А. Андреев // Преодоление конфликтных ситуаций в процессе раскрытия и расследования преступлений : сб. науч. тр. - Екатеринбург : Изд-во Урал. юрид. ин-та МВД России, 2005. С. 16-18.

5. Волчецкая Т. С. Теоретические проблемы использования метода моделирования в криминалистической науке / Т. С. Волчецкая // Социальные и гуманитарные науки на Дальнем Востоке. - 2012. - № 4 (36). - С. 16-20.

6. Бедризов А. Г. Проблемы допустимости тактических приемов, используемых при допросе свидетелей / А. Г. Бедризов // Вестник Балтийского федерального университета им. И. Канта. - 2014. - Вып. 9. - С. 121-127.

7. Протасевич А. А. Монологи. Криминалисты о своей науке, призванной адекватно противостоять современной преступности / А. А. Протасевич, В. А. Образцов, С. Н. Богомолова. - Иркутск : Изд-во ИГЭА, 1999. - 106 с.

8. Эминов В. С. Следственные действия - основа раскрытия преступлений: психолого-криминалистический анализ : практ. пособие / В. С. Эминов, Е. П. Ищенко. - М. : Норма : Инфра-М, 2015. - 93 с.

9. Ищенко Е. П. Криминалистика : Курс лекций / Е. П. Ищенко. - М. : Контракт : АСТ-Москва, 2007. - 243 с.

\section{Baikal Research Journal}


10. Головин А. Ю. Механизм коррупционных преступлений, совершаемых путем подкупа, и установление его элементов в ходе допроса / А. Ю. Головин, Н. В. Бугаевская // Известия Тульского государственного университета. Экономические и юридические науки. - 2013. - № 5-2. - С. 6-13.

11. Варданян А. В. Использование знаний о способах преступлений против жизни и здоровья в выявлении и разоблачении ложного алиби / А. В. Варданян, О. Н. Алексиенко // Юристъ-Правоведъ. - 2008. - № 6. - С. 35-39.

12. Чебуренков А. А. «Косвенный допрос» как разновидность тактической комбинации при расследовании преступлений / А. А. Чебуренков // Организация деятельности органов расследования преступлений: управленческие, правовые и криминалистические аспекты (к 60-летию каф. упр. органами расследования преступлений) : материалы Междунар. науч.-практ. конф. : в 2 ч. - М. : Акад. упр. МВД России, 2015. - Ч. 2. - 420 с.

\section{References}

1. Bayev O. Ya. On methodology of investigative tactics (causes of investigative errors). Zakony Rossii: opyt, analiz, praktika = Law of Russia: Experience, Analysis, Practice, 2015, no. 2, pp. 70-78. (In Russian).

2. Rossinsky S. B. Concept and essence of investigative actions in criminal proceedings: the debate continues. Zakony Rossii: opyt, analiz, praktika = Law of Russia: Experience, Analysis, Practice, 2015, no. 2, pp. 16-31. (In Russian).

3. Pelenitsin A. B. On scientific justification of using the polygraph. Ekspert-kriminalist $=$ Expert-Criminalist, 2011, no. 2, pp. 12-15. (In Russian).

4. Andreyev A. A. Tactics of interrogating the suspect in complicated investigative situations. Preodolenie konfliktnykh situatsii $v$ protsesse raskrytiya $i$ rassledovaniya prestuplenii [Overcoming conflict situations in detecting and investigating crimes]. Yekaterinburg, Ural State Law Institute of the Ministry of Internal Affairs of the Russian Federation Publ., 2005, pp. 16-18. (In Russian).

5. Volchetskaya T. S. Theoretical issues in using modeling method in criminology. Sotsial'nye $i$ gumanitarnye nauki na Dal'nem Vostoke = The Humanities and Social Studies in the Far East, 2012, no. 4 (36), pp. 16-20. (In Russian).

6. Bedrizov A. G. Admissibility of techniques used in interrogating witnesses. Vestnik Baltiiskogo federal'nogo universiteta im. I. Kanta = Bulletin of I. Kant Baltic Federal University, 2014, iss. 9, pp. 121-127. (In Russian).

7. Protasevich A. A., Obraztsov V. A., Bogomolova S. N. Monologi. Kriminalisty o svoei nauke, prizvannoi adekvatno protivostoyat' sovremennoi prestupnosti [Monologues. Criminalists about their work destined to adequately stand against today's criminality]. Irkutsk State Economics Academy Publ., 1999. 106 p.

8. Eminov V. S., Ishchenko E. P. Sledstvennye deistviya - osnova raskrytiya prestuplenii: psikhologo-kriminalisticheskii analiz [Interrogating actions as a basis of detecting crimes: psychological and criminalistics analysis]. Moscow, Norma Publ., Infra-M Publ., 2015. 93 p.

9. Ishchenko E. P. Kriminalistika: Kurs lektsii [Criminalistics. Lectures]. Moscow, Kontrakt Publ., AST-Moskva Publ., 2007. 243 p.

10. Golovin A. Yu., Bugayevskaya N. V. Mechanism of corruption crimes, committed by means of bribery, and establishment of its elements during interrogation. Izvestiya Tul'skogo gosudarstvennogo universiteta. Ehkonomicheskie $i$ yuridicheskie nauki = Bulletin of Tula State University. Economic and Legal Sciences, 2013, no. 5-2, pp. 6-13. (In Russian).

11. Vardanyan A. V., Aleksiyenko O. N. Use of knowledge about means of crimes against life and health in discovering false alibi. Yurist-Pravoved $=$ Lawyer-Legal Scholar, 2008, no. 6, pp. 35-39. (In Russian).

12. Cheburenkov A. A. «Indifferent interrogation» as a variety of tactical combination in investigating crimes. Organizatsiya deyatel'nosti organov rassledovaniya prestuplenii: upravlencheskie, pravovye $i$ kriminalisticheskie aspekty. Materialy mezhdunarodnoi nauchno-prakticheskoi konferentsii [Organization of activity of criminal investigating bodies: managerial, legal and criminalistics aspects. Materials of International Research Conference]. Moscow, Academy of Management of Russian Ministry of Internal Affairs Publ., 2015. Pr. 2. 420 p. (In Russian).

\section{Baikal Research Journal}




\section{Информация об авторах}

Ишигеев Владимир Степанович - доктор юридических наук, профессор, кафедра уголовного права и криминологии, Байкальский государственный университет, 664003, г. Иркутск, ул. Ленина, 11.

Паршин Длитрий Викторович - адъюнкт, Восточно-Сибирский институт Министерства внутренних дел Российской Федерации, 664074, г. Иркутск, ул. Лермонтова, 110; e-mail: pdv20141@mail.ru.

\section{Authors}

Vladimir S. Ishigeyev - Doctor habil. (Law), Professor, Chair of Criminal Law and Criminology, Baikal State University, 11 Lenin St., 664003, Irkutsk, Russian Federation.

Dmitry V. Parshin - Adjunct, East-Siberian Institute of Ministry of Interior Affairs, 110 Lermontov St., 664074, Irkutsk, Irkutsk, Russian Federation; e-mail: pdv20141@mail.ru.

\section{Библиографическое описание статьи}

Ишигеев В. С. Использование приемов психотерапии и релаксации в ходе проведения допросов при расследовании преступлений по факту хищений бюджетных средств / В. С. Ишигеев, Д. В. Паршин // Baikal Research Journal. - 2017. — T. 8, № 1. — DOI: 10.17150/2411-6262.2017.8(1).21.

\section{Reference to article}

Ishigeyev V. S., Parshin D. V. Using methods of psychotherapy and relaxation in investigating crimes in the course of interrogation upon embezzlement of public funds. Baikal Research Journal, 2017, vol. 8, no. 1. DOI: 10.17150/2411-6262.2017.8(1).21. (In Russian).

\section{Baikal Research Journal}

